TI 2006-025/2

Tinbergen Institute Discussion Paper

Central Bank Instruments, Fiscal

Policy Regimes, and the

Requirements for Equilibrium

Determinacy

Andreas Schabert 


\section{Tinbergen Institute}

The Tinbergen Institute is the institute for economic research of the Erasmus Universiteit Rotterdam, Universiteit van Amsterdam, and Vrije Universiteit Amsterdam.

Tinbergen Institute Amsterdam

Roetersstraat 31

1018 WB Amsterdam

The Netherlands

Tel.: $\quad+31(0) 205513500$

Fax: $\quad+31(0) 205513555$

Tinbergen Institute Rotterdam

Burg. Oudlaan 50

3062 PA Rotterdam

The Netherlands

Tel.: $\quad+31(0) 104088900$

Fax: $\quad+31(0) 104089031$

Please send questions and/or remarks of nonscientific nature to driessen@tinbergen.nl.

Most TI discussion papers can be downloaded at http://www.tinbergen.nl. 


\title{
Central Bank Instruments, Fiscal Policy Regimes, and the Requirements for Equilibrium Determinacy ${ }^{1}$
}

\author{
Andreas Schabert ${ }^{2}$ \\ University of Amsterdam
}

February 28, 2006

\begin{abstract}
This paper examines the role of the monetary instrument choice for local equilibrium determinacy under sticky prices and different fiscal policy regimes. Corresponding to Benhabib et al.'s (2001) results for interest rate feedback rules, the money growth rate should not rise by more than one for one with inflation when the primary surplus is raised with public debt. Under an exogenous primary surplus, money supply should be accommodating - such that real balances grow with inflation - to ensure local equilibrium determinacy. When the central bank links the supply of money to government bonds by controlling the bond-to-money ratio, an inflation stabilizing policy can be implemented for both fiscal policy regimes. Local determinacy is then ensured when the bond-to-money ratio is not extremely sensitive to inflation, or when interest payments on public debt are entirely tax financed, i.e., the budget is balanced.
\end{abstract}

JEL classification: E52, E63, E32.

Keywords: Fiscal-monetary policy interaction, money growth, bond-to-money ratio, local equilibrium determinacy.

\footnotetext{
${ }^{1}$ The author would like to thank Roel Beetsma, Naomi Leefmans, Ludger Linnemann, Leopold von Thadden, and two anonymous referees for helpful comments. This research is part of the RTN project "Macroeconomic Policy Design for Monetary Unions", funded by the European Commission (contract number HPRNCT-2002-00237). The usual disclaimer applies.

${ }^{2}$ Address: University of Amsterdam, Department of Economics, Roeterstraat 11, 1018 WB Amsterdam, The Netherlands, Phone: +31 20525 7159, Fax: +31 20525 4254, E-mail: a.schabert@uva.nl.
} 


\section{Introduction}

The central bank can conduct monetary stabilization policy by using different instruments. The choice of a particular instrument can affect its ability to stabilize macroeconomic aggregates and can thus matter for social welfare. This has been shown by Poole (1970), Sargent and Wallace (1975), and, more recently, by Carlstrom and Fuerst (1995), Gavin et al. (2004), and Collard and Dellas (2005). These studies do not lead to an unambiguous conclusion about which instrument to prefer. Yet, contemporary research on monetary policy primarily focuses on the analysis of interest rate rules. One major question in this literature is how particular interest rate feedback rules affect local equilibrium determinacy under different specifications of preferences, markets, and technologies. ${ }^{3}$ Other studies have shown that equilibrium determinacy is to an important extent affected by interactions between monetary and fiscal policy. Seminal contributions to this literature are Leeper (1991), Sims (1994), and Woodford (1994, 1995), which have established the 'Fiscal Theory of the Price Level' (FTPL). ${ }^{4}$ According to the FTPL, the price level can be determined by the needs of government solvency when monetary policy fails to provide a nominal anchor. When prices are sticky, fiscal policy can further be crucial for existence and uniqueness of the equilibrium allocation, and can severely constrain the conduct of interest rate policy, as shown by Benhabib et al. (2001). This paper combines the two strands of research, and analyses the fiscal policy impact on the determination of local equilibrium paths for cases where the central bank applies instruments other than the interest rate.

As the main novel contribution to the literature, this paper examines local equilibrium determinacy under staggered price setting when the central bank adjusts the supply of money in response to changes in inflation under different fiscal policy regimes. ${ }^{5}$ We consider the cases where the central bank controls the supply of money either according to a money growth rate rule or according to a rule that links the outstanding stocks of money and government bonds. Like in Benhabib et al. (2001), we further consider fiscal policy regimes that differ with regard to the feedback from public debt to the primary surplus. We find that when the central bank follows a money growth feedback rule, the fiscal stance is decisive for the way the central bank has to adjust the money growth rate in order to ensure local uniqueness of equilibrium. If the primary surplus rises with debt, the government finance decision is irrelevant for the equilibrium allocation and the price system. Local equilibrium determinacy then requires the money growth rate to rise by less than one for one with inflation, implying that real balances

\footnotetext{
${ }^{3}$ Examples are Benhabib et al. (2001), Carlstrom and Fuerst (2001, 2005), Dupor (2001a), Woodford (2001), Meng, (2002), Brueckner and Schabert (2003), or De Fiore and Liu (2005).

${ }^{4}$ See Kocherlakota and Phelan (1999), Christiano and Fitzgerald (2000), or Woodford (2001) for comprehensive discussions, Buiter (2002) or Niepelt (2004) for critical assessments, and Cochrane (2003) for approval.

${ }^{5}$ Our analysis relates to Black (1974), who examines price level determination when the central bank raises the money growth rate in response to an increase in inflation, and to Woodford (1994), who analyses determinacy for a constant money growth policy and different fiscal policy regimes in a flexible price framework.
} 
decrease with inflation. If the fiscal policy regime is instead characterized by an exogenous primary surplus, fiscal policy matters and government solvency imposes a relevant restriction on the price level and (due to sticky prices) on the equilibrium allocation. Under this fiscal policy regime local equilibrium determinacy requires real balances to increase with inflation, such that unstable debt dynamics are avoided by an accommodating money supply, which devaluates debt. This corresponds to Benhabib et al.'s (2001) result that interest rate policy should be passive when the primary surplus is exogenous.

The conclusions regarding the requirements for local equilibrium determinacy and the role of fiscal policy fundamentally change when the central bank supplies money contingent on the outstanding stock of government bonds. ${ }^{6}$ By using the ratio of outstanding bonds to money as its operating target, the central bank links the stocks of public liabilities that are typically traded in open market operations. As long as the bond-to-money ratio is finite, government solvency is guaranteed for both fiscal policy regimes. Since money supply is linked to government bonds, a change in the latter affects households' willingness to consume, such that fiscal policy is non-neutral. Thus, the equilibrium allocation and the price system depend on the evolution of debt, and real financial wealth becomes a relevant predetermined state variable. Local equilibrium determinacy is ensured if the bond-to-money ratio is not strongly raised in response to higher inflation, or if the fiscal authority conducts a balance budget policy. The evolution of real wealth then exerts a stabilizing impact, as it avoids indeterminacy or unstable dynamics.

Hence, fiscal policy can impose substantial restrictions on the conduct of monetary policy if the central bank controls the nominal interest rate or the money growth rate. If the primary surplus is exogenous, the central bank should abstain from a strong monetary tightening whenever inflation rises. Such a policy, which would stabilize inflation when debt is neutral, leads to local indeterminacy or instability when debt interest payments are not tax financed. In this case, money growth policy should instead accommodate inflation and interest rate policy should be passive, which both allow for strong inflation fluctuations and therefore lead to welfare costs due to the price rigidity. In contrast, a bond-to-money policy can always be conducted in a way that is consistent with the aim to stabilize inflation in the short-run. However, fiscal policy then affects the long-run inflation rate and therefore the welfare costs due to average price changes. These can be minimized by a balanced budget policy, which further guarantees local equilibrium determinacy for any positive bond-to-money ratio.

The paper is organized as follows. Section 2 presents the model. In the first part of section 3, we briefly examine price level determination and conditions for local determinacy of equilibrium paths under flexible prices, which have until now not been analyzed for the

\footnotetext{
${ }^{6}$ This instrument has also been applied in Wallace (1984), Schreft and Smith (1998, 2000), Battacharya and Kudoh (2002), and in Kaas and Weinrich (2003) in flexible price models.
} 
two money supply regimes. In the second and main part of section 3, we derive conditions for local equilibrium determinacy under sticky prices. Section 4 concludes.

\section{The model}

This section presents a general equilibrium model with sticky prices. Nominal variables are denoted by upper-case letters, while real variables are denoted by lower-case letters.

\subsection{The private sector}

The economy is populated by a continuum of identical households. Following Sidrauski (1967), we introduce real balances in the utility function of households as a short-cut for assuming that they provide transaction services. The utility function is further assumed to be separable with regard to all arguments. ${ }^{7}$ A representative household is infinitely lived, with preferences given by the value of a discounted stream of instantaneous utility $u($.

$$
\int_{0}^{\infty} e^{-\theta t} u(c, l, m) d t, \quad u(c, l, m)=\frac{c^{1-\sigma_{c}}}{1-\sigma_{c}}-\frac{l^{1+\sigma_{l}}}{1+\sigma_{l}}+\log (m)
$$

where $\sigma_{c}>0$ and $\sigma_{l} \geq 0$, and $c$ denotes consumption, $l$ working time, $m=M / P$ real balances, $M$ cash, $P$ the aggregate price level, and $\theta>0$ the instantaneous discount rate. Households are endowed with financial wealth denoted by $A$, which can be held in form of cash $M$ or interest bearing government bonds $B: A=M+B$. Their income comprises labor remuneration, interest earnings from bond holdings, and profits of firms which are owned by the households. The budget constraint of a representative household reads in real terms

$$
\dot{a} \leq(R-\pi) a-R m+w l-c-\tau+\psi
$$

where $a=A / P, w, \tau, R, \pi$, and $\psi$ denote real financial wealth, the real wage rate, a lump sum tax, the nominal interest rate, the inflation rate, and real profits of firms, respectively. The household maximizes (1) by choosing paths for consumption, leisure, real balances, and real wealth, for given initial values $A_{0}>0,{ }^{8}$ subject to (2) and to a no-Ponzi-game condition, taking prices, public policy, and profits of firms as given. The first order conditions are given by

$$
l^{\sigma_{l}}=w c^{-\sigma_{c}}, \quad m=c^{\sigma_{c}} / R, \quad \dot{c} / c=(R-\pi-\theta) / \sigma_{c},
$$

the transversality condition $\lim _{t \rightarrow \infty} a(t) \exp \left[-\int_{0}^{t}(R(v)-\pi(v)) d v\right]=0$, and the budget constraint (2) holding with equality.

\footnotetext{
${ }^{7}$ Though we are aware of the fact that non-separability of $u($.$) matters for real determinacy, as shown in$ Matheny (1998), Benhabib et al. (2001), or Carlstrom and Fuerst (2003), separability is assumed for simplicity.

${ }^{8}$ It should be noted that the assumption of positive initial wealth is not harmless for the determination of the initial price level. See Niepelt (2004) for a discussion of potential inconsistencies with the concept of a rational expectations equilibrium, where the initial asset issuance is explicitly taken into account.
} 
There is a continuum of monopolistically competitive firms. Each firm $i \in[0,1]$ supplies a single differentiated good $y_{i}$, which are inputs into the production of the composite final good. The latter is produced by perfectly competitive firms. The aggregation technology for the final good $y$ is given by: $y^{(\varepsilon-1) / \varepsilon}=\int_{0}^{1} y_{i}^{(\varepsilon-1) / \varepsilon} d i$, where $\varepsilon>1$ and $y_{i}$ denotes the quantity of the $i$-th differentiated good. Each firm $i$ produces exactly one variant of the differentiated output good $y_{i}$. The cost minimizing demand for intermediate good $i$ is given by $y_{i}=\left(P_{i} / P\right)^{-\varepsilon} y$, with $P^{1-\varepsilon}=\int_{0}^{1} P_{i}^{1-\varepsilon}$, where $P_{i}$ denotes the price of the differentiated good indexed with $i$. The production technology of a firm $i$ is given by $y_{i}=l_{i}$.

We introduce staggered price setting as in Calvo (1983). Firms set their prices to maximize a discounted stream of current and future real profits. They are assumed to be able to adjust prices only when they receive a random signal. Otherwise, they set their prices along with the inflation rate $\bar{\pi}$ given an initial value for the price level $P_{0}>0 .{ }^{9}$ The time interval until the arrival of a random price-change signal is exponentially distributed such that the probability of not being allowed to adjust prices between dates $t$ and $s>t$ is $\exp (-\delta[s-t])$, with $\delta>0$. In period $t$ a firm $i$ receiving a price signal sets the price $Q_{t}$, where the index $i$ is dropped from $Q_{t}$, since all firms receiving a signal will behave identically. The maximization problem is given by $\max _{Q_{t}} \int_{t}^{\infty} e^{-(\delta+\theta)(s-t)} \lambda_{s}\left[\left(Q_{t} e^{\bar{\pi}(s-t)} y_{i s}\left(Q_{t}\right)-P_{s} w_{s} n_{i s}\left(Q_{t}\right)\right) / P_{s}\right] d s$, subject to $y_{i s}\left(Q_{t}\right)=\left(Q_{t} e^{\bar{\pi}(s-t)}\right)^{-\varepsilon} P_{s}^{\varepsilon} y_{s}$, where profits are discounted with the probability of not adjusting $e^{-\delta(s-t)}$ and weighted with $\lambda_{s} e^{-\theta(s-t)} \cdot{ }^{10}$

Suppose that there exists a steady state. Then a linear approximation of the firms' first order conditions and the price indices at this steady state leads to the aggregate supply constraint (see Appendix A)

$$
\dot{\pi}=\theta(\pi-\bar{\pi})-\delta(\delta+\theta) \frac{\varepsilon}{\varepsilon-1}(w-\bar{w}),
$$

where $\bar{x}$ denotes the steady state value of $x=\pi, w$. Equation (4) is a continuous time version of the 'New Keynesian Phillips Curve'.

\subsection{The public sector}

The public sector consists of a fiscal authority and a central bank. The fiscal authority issues riskless bonds of immediate maturity, pays interest on outstanding debt, and collects lump-sum taxes from households. We normalize (for simplicity) government purchases of goods to equal zero, such that the primary surplus equals the tax receipts. The central bank issues money. The consolidated period-by-period government budget constraint is given by

\footnotetext{
${ }^{9}$ It should be noted that the initial price level is only relevant for the firms' problem in the case where prices are not completely flexible. When firms can adjust prices in a perfectly flexible way, their pricing decision does evidently not depend on $P_{0}$.

${ }^{10}$ The latter can be motivated by the assumption that the manager of the firm exhibits the same preferences as the owners, i.e., the households. Alternatively, firms and households can be assumed to have access to a complete set of contingent claims.
} 
$\dot{B}+\dot{M}=R B-P \tau$ and in terms of total liabilities $S=B+M$ :

$$
\dot{S}=R S-R M-P \tau
$$

In real terms, (5) reads $\dot{s}=(R-\pi) s-R m-\tau$, where $s=S / P$ denotes real liabilities. We consider three different monetary policy instruments, which are all set contingent on the current inflation rate. The first regime is characterized by the central bank setting the nominal interest rate on government bonds. Following Benhabib et al. (2001), we assume that the interest rate $(I R)$ is set according to

$$
\text { IR policy : } R=\rho(\pi) \text {. }
$$

An $I R$ policy is further assumed to ensure that the nominal interest rate exceeds its lower bound $\rho>0$. For the second monetary policy regime we assume that the central bank adjusts the stock of money according to a growth rate rule. In contrast to related studies where the growth rate is assumed to be exogenous (see, e.g., Woodford, 1994, or Carlstrom and Fuerst, 2003), we allow the money growth $(M G)$ rate to be set contingent on inflation. ${ }^{11}$ Thus, the central bank supplies money according to

$$
M G \text { policy : } \quad \dot{M} / M=\mu(\pi)
$$

with an initial value $M_{0}>0$. We further assume that a $M G$ policy satisfies $\mu>-\theta$, which ensures the existence of an equilibrium with a positive nominal interest rate. The third regime is characterized by the central bank linking the supply of money to the outstanding stock of government bonds, which are both traded in open market operations. ${ }^{12}$ Again, the policy instrument, i.e., the bond-to-money $(B M)$ ratio, is set contingent on current inflation:

$$
B M \text { policy : } B / M=\beta(\pi)
$$

A $B M$ policy is further assumed to satisfy $\beta>-1$. This assumption ensures that a steady state with a positive nominal interest rate exists, and that the public sector is a net debtor $S>0$. Finally, we assume that the policy rules (6)-(8) take the following values for the steady state inflation rate $\bar{\pi}: \rho(\bar{\pi})=\bar{R}, \mu(\bar{\pi})=\bar{\mu}$, and $\beta(\bar{\pi})=\bar{\beta}$.

Turning back to the fiscal authority, we assume that the government levies lump-sum taxes to finance a fraction of interest payment obligations on outstanding debt. Hence, the

\footnotetext{
${ }^{11}$ An exception is Black (1974) who considers the case of an "adaptive money supply", where the money growth rate $\mu$ satisfies $\partial \mu / \partial \pi>1$.

${ }^{12}$ This instrument has, for example, also been applied by Schreft and Smith $(1998,2000)$ for the analysis of equilibrium stability in monetary overlapping generation models.
} 
primary surplus satisfies the following simple feedback rule:

$$
P \tau=\kappa R B, \quad \kappa \in[0,1]
$$

We are particularly interested in two fiscal policy regimes, which are commonly considered in related studies on monetary and fiscal policy interactions (see Benhabib et al., 2001, SchmittGrohe and Uribe, 2000, or Woodford, 2001). The first fiscal policy regime is characterized by a strictly positive feedback from debt to the primary surplus $\kappa>0$. The second fiscal policy regime is characterized by a primary surplus that does not respond to changes in public debt, $\kappa=0$. To see the main difference between these two regimes, we integrate the period-by-period government budget constraint (5)

$$
S_{0} / P_{0}=\int_{0}^{\infty} e^{-\int_{0}^{t}[R(v)-\pi(v)] d v}[R(t) m(t)+\tau(t)] d t+\lim _{t \rightarrow \infty} s(t) e^{-\int_{0}^{t}[R(v)-\pi(v)] d v},
$$

where $S_{0}>0$ is given. Government solvency requires that liabilities are not rolled over infinitely, i.e., that real liabilities grow with a rate that is smaller than the real interest rate, $\lim _{t \rightarrow \infty} s(t) \exp \left(-\int_{0}^{t}[R(v)-\pi(v)] d v\right)=0$. Substituting out taxes in (5) by the fiscal policy rule (9) gives

$$
\dot{S}=(1-\kappa) R(S-M)
$$

which leads to a growth rate of real liabilities equal to $\dot{s} / s=((1-\kappa) R-\pi)-(1-\kappa) R m / s$. Thus, fiscal policy does not ensure government solvency off equilibrium, since the growth rate of $s$ is not necessarily smaller than the real interest rate. In equilibrium, real balances and real liabilities are positive (given that $s_{0}>0$ ), which implies that government solvency can in principle be violated if $\kappa=0$ and $s$ grows faster than $m$, so that $s$ asymptotically grows with real interest rate. Hence, when fiscal policy is characterized by $\kappa=0$, the household transversality condition, which equals government solvency in equilibrium $(a=s)$, can become a relevant equilibrium condition. If, however, tax revenue is a positive fraction of debt interest services, $\kappa>0$, real government liabilities $s$ grow with a smaller rate in equilibrium and their discounted value converges for $t \rightarrow \infty$ to zero. The transversality condition will then not be a binding equilibrium condition, and fiscal policy, i.e., the stock of government bonds and the timing of taxes, is neutral with regard to the equilibrium allocation and the price system. ${ }^{13}$

Assuming that taxes equal a constant $\tau=\bar{\tau}>0$ (instead of $\tau=0)$, like in Benhabib et al. (2001), would leave the main conclusions unchanged. Throughout the analysis, we refer to a regime with $\kappa=0$ as a fiscal policy with an exogenous primary surplus and to a regime with

\footnotetext{
${ }^{13}$ It should be noted that this fiscal policy regime does not exactly accord to the fiscal policy regimes in Kocherlakota and Phelan (1999) or Benhabib et al. (2001), where the corresponding policy regime ensures government solvency even off equilibrium.
} 
$\kappa>0$ as a fiscal policy with a primary surplus that rises with debt. ${ }^{14} \mathrm{~A}$ specification of fiscal policy with an exogenous primary surplus has often been blamed to be less reasonable or empirically less plausible (see Buiter, 2002, Canzoneri et al., 2002, Niepelt, 2004). Here, we do not take a stand on the plausibility of the fiscal regimes, ${ }^{15}$ and focus on the implications of different fiscal policy regimes for the requirements for local equilibrium determinacy under different monetary policy instruments.

\section{Monetary-fiscal policy regimes and local equilibrium determinacy}

In this section we derive conditions for local equilibrium determinacy, i.e., for the determination of bounded equilibrium paths that converge to the steady state, for monetary policy regimes satisfying either (6), (7) with $M_{0}>0$, or (8), and for a fiscal policy regime satisfying (11). For this, we linearize the equilibrium conditions at the steady state. In a neighborhood of the steady state the equilibrium paths are then approximated by the solutions to the linearized equilibrium conditions. Throughout the paper, we abstract from problems stemming from the nominal interest rate hitting its lower bound. ${ }^{16}$

When the central bank controls the nominal interest rate (6) or the money growth rate (7) the steady state is characterized by constant values for consumption, real balances, inflation, and for the interest rate satisfying

$$
\bar{c}=[(\varepsilon-1) / \varepsilon]^{1 /\left(\sigma_{c}+\sigma_{l}\right)}, \quad \bar{m}=\bar{c}^{\sigma_{c}} / \bar{R}, \quad \bar{R}=\bar{\pi}+\theta
$$

and either $\bar{R}=\rho(\bar{\pi})$ or $\bar{\pi}=\mu(\bar{\pi})$. For a $M G$ policy, the assumption $\mu>-\theta$ ensures the existence of a steady state with $\bar{R}>0$. The steady state values are independent of fiscal policy, i.e., they are unaffected by taxes and real government bonds for $\kappa \geq 0$. This is different in the case where the central bank sets the bond-to-money ratio, which links the real value of real government liabilities (by $s=m(1+\beta)$ ) to real money and (by $c^{\sigma_{c}}=m R$ ) to consumption. Thus, stationary equilibrium paths for consumption, real balances, inflation, and the interest rate require real government liabilities also to be stationary. The steady state is then characterized by paths for $c, m, \pi, R$, and real wealth $a=s$ satisfying (12), $\bar{a}=(1+\beta(\bar{\pi})) \bar{m}$ and $\bar{R}=\theta \frac{1+\beta(\bar{\pi})}{1+\kappa \beta(\bar{\pi})}$. The latter, which originates in (11), implies that the steady state nominal interest rate is strictly positive $\bar{R}>0$, given that $\beta$ has been restricted

\footnotetext{
${ }^{14}$ Schmitt-Grohe and Uribe (2000), for example, refer to the latter case, as a fiscal policy with an "endogenous primary surplus". As suggested by an anonymous referee, an endogenous primary surplus in principle encompasses the case $\kappa<0$. Evidently, such a policy does not ensure government solvency, like a policy with an exogenous primary surplus, $\kappa=0$. Nevertheless, it is in general associated with different determinacy implications than an exogenous primary surplus. Under flexible prices, for instance, the price level can(not) be determined for an IR policy if $\kappa=0(\kappa<0)$.

${ }^{15}$ Woodford (2001) presents the US bond-price-support regime 1942-1951 as an example for a fiscal determination of the price level.

${ }^{16}$ Hence, we focus on the case where the nominal interest rate is strictly positive $R>0$, such that the demand for money, $m=c^{\sigma_{c}} / R$, is well defined.
} 
to satisfy $\beta>-1$ and that $\kappa \geq 0$.

It should be noted that the steady state inflation rate solely depends on monetary policy in the $I R$ and the $M G$ case, whereas it also depends on fiscal policy in the $B M$ case. Combining the steady state conditions for the latter case, leads to $\bar{\pi}=\theta(1-\kappa) \frac{\beta(\bar{\pi})}{1+\kappa \beta(\bar{\pi})}$, which shows that the steady state inflation rate decreases with the fiscal policy feedback $\kappa$ and equals zero for a balanced budget policy, $\kappa=1 \Rightarrow \bar{\pi}=0$.

\subsection{Government solvency and the price level}

Before we turn to the sticky price case, we briefly assess the determination of the price level and the conditions for the uniqueness of equilibrium paths that converge to the steady state in the flexible price case. Since prices are set in a forward-looking way, there might exist multiple initial price levels $P_{0}$ that are consistent with the equilibrium allocation. For the local determinacy analysis we restrict our attention to equilibrium paths that are approximated by the solutions to the equilibrium conditions, which are linearized at the steady state. The local equilibrium determinacy conditions, which have until now not been analyzed for the $M G$ and the $B M$ case, ${ }^{17}$ are derived in Appendix B and presented in table 1.

When prices are perfectly flexible $(\delta \rightarrow \infty), w=(\varepsilon-1) / \varepsilon$ and $y=c=l$, implying that consumption is constant and equals its steady state value $\bar{c}$ (see 12 ). The equilibrium can then be summarized as follows: ${ }^{18}$ A perfect foresight equilibrium under flexible prices consists of an initial price level $P_{0}>0$ and a set of paths for consumption, real balances, the nominal interest rate, inflation, real wealth, and taxes $\{c, m, R, \pi, a, \tau\}$ that converge to the steady state and satisfy $c=\bar{c}, R=\pi+\theta, m=c^{\sigma_{c}} / R, \dot{a}=[(1-\kappa) R-\pi] a-(1-\kappa) R m$, the transversality condition, a monetary policy (6), (7) with $M_{0}>0$, or (8), and a fiscal policy (9), given $A_{0}>0$.

In accordance with the FTPL, fiscal policy is decisive for the determination of the equilibrium price level under $I R$ policy (see Kocherlakota and Phelan, 1999). Since the central bank does not provide a nominal anchor, the price level and the equilibrium paths can only be determined if the primary surplus is exogenous. In equilibrium, where the transversality condition has to be satisfied, the intertemporal government budget constraint (10) and market clearing $A=S$ imply

$$
A_{0} / P_{0}=\int_{0}^{\infty} \exp \left(-\int_{0}^{t}[R(v)-\pi(v)] d v\right)[R m+\tau] d t .
$$

When the primary surplus rises with debt, $\kappa>0$, there are infinitely many pairs $\{a, \tau\}$

\footnotetext{
${ }^{17}$ An exception is Black (1974) who shows that the price level is indetermined in a flexible price model under a money growth rule of the type (7) satisfying $\mu_{\pi}>1$.

${ }^{18}$ For a given inflation path $\{\pi\}$, a particular initial price level $P_{0}>0$ leads to a uniquely determined price level path $\{P\}$.
} 
satisfying (9) that are consistent with a particular set of equilibrium paths $\{c, m, R, \pi\}$, such that $P_{0}$ is not uniquely determined by (13) for a given initial stock of wealth $A_{0}>0$. If however the primary surplus is exogenous, $\kappa=0 \Rightarrow \tau=0$, there exist exactly one initial price level $P_{0}$ and one real wealth path $\{a\}$ consistent with a particular set of equilibrium paths $\{c, m, R, \pi\}$ and a given $A_{0}>0$. Yet, fiscal policy does not affect the determination of equilibrium paths $\{c, m, R, \pi\}$, which are locally determined if $\rho_{\pi}=\partial \rho / \partial \pi \neq 1$ (see Appendix B, or Benhabib et al., 2001). Thus, local equilibrium determinacy requires $\rho_{\pi} \neq 1$ and an exogenous primary surplus (see table 1). A regime satisfying $\kappa>0$ and $\rho_{\pi} \neq 1$ leads to a locally determined set of paths $\{c, m, R, \pi\}$, while leaving $P_{0}$ and $\{a, \tau\}$ indetermined.

For the two money supply rules (7) and (8) the equilibrium determinacy properties exhibit substantial differences. Under a $M G$ policy, (7) with $M_{0}>0$, the central bank provides a nominal anchor $(M)$, such that there exists exactly one price level path that is consistent with a particular set of paths $\{m, \pi\}$. This however implies that the equilibrium price level cannot freely jump in accordance with the demands for government solvency. As shown in Appendix B, money growth thus has to accommodate inflation, $\mu_{\pi}=\partial \mu / \partial \pi>1$, to ensure local equilibrium determinacy for $\kappa=0$. In contrast, when the primary surplus rises with debt, $\kappa>0$, local equilibrium determinacy requires real money to decrease with inflation, $\mu_{\pi}<1 .{ }^{19}$

Under a $B M$ policy the initial price level $P_{0}$ is also uniquely determined for a particular set of equilibrium paths $\{c, m, R, \pi\}$ : Using the policy rule (8) and $\bar{c}^{\sigma_{c}}=m R$, (11) can be written as $\dot{S}=(1-\kappa) \frac{\bar{c}^{\sigma_{c}}}{m} \frac{\beta(\pi)}{1+\beta(\pi)} S$, which uniquely determines a nominal liabilities path $\{S\}$ for a given initial value $S_{0}>0$ and a set of equilibrium paths $\{c, m, R, \pi\}$. The latter are further associated with a unique path for real wealth satisfying $a=(1+\beta(\pi)) m$, such that a price level path is uniquely determined by $P=S / a$. The set of equilibrium paths $\{c, m, R, \pi, a, \tau\}$ is locally determined if (but not only if) the central bank sets the bondto-money ratio according to $\beta_{\pi}=\partial \beta / \partial \pi<1 / \theta$ (see in Appendix B). Notably, for a $B M$ policy local determinacy can be ensured by monetary policy regardless of whether the primary surplus is exogenous or rises with debt. A crucial difference to the $I R$ and the $M G$ regime can be seen from combining (8) and (11) to

$$
\dot{s}=\left[(1-\kappa) \frac{\beta(\pi)}{1+\beta(\pi)} R-\pi\right] s .
$$

According to (14), real government liabilities grow with a rate that is strictly smaller than the real interest rate $R-\pi$ for any $\kappa \geq 0$ (given that $\beta>-1$ ). Hence, under a $B M$ policy government solvency is ensured even off equilibrium, i.e., monetary policy guarantees that

\footnotetext{
${ }^{19}$ These results are consistent with Black's (1974) inderminacy result for $\mu_{\pi}>1$, and with Woodford's (1994) result of price level instability for a constant money growth rate $\left(\bar{\mu}_{\pi}=0\right)$ under an exogenous primary surplus.
} 
$\lim _{t \rightarrow \infty} s(t) \exp \left(-\int_{0}^{t}[R(v)-\pi(v)] d v\right)=0$ holds for a fiscal policy (9) with $\kappa \geq 0$. Thus, under a $B M$ policy there is no qualitative change in the local equilibrium determinacy properties when fiscal policy shifts from a regime characterized by a primary surplus that rises with debt, $\kappa>0$, to an exogenous primary surplus, $\kappa=0$.

\subsection{Local equilibrium determinacy under sticky prices}

In this section we examine how monetary and fiscal policy affect the determination of equilibrium paths that converge to the steady state for the more realistic case where prices are not completely flexible. There is no degree of freedom with regard to the price level in this case. Prices now evolve in a history dependent way for some given initial price level $P_{0}>0$, on which the price adjustment of those firms is based that do not set prices in an optimizing way. Nevertheless, whether the primary surplus is exogenous, $\kappa=0$, or rises with debt, $\kappa>0$, matters for local equilibrium determinacy under an $I R$ or a $M G$ policy. In contrast, monetary policy can ensure local equilibrium determinacy under a $B M$ policy for a fiscal policy satisfying (9) with $\kappa>0$ or $\kappa=0$. Key to this result is that only the $B M$ policy guarantees government solvency regardless of the primary surplus, as shown above. To provide an overview, Table 2 summarizes the necessary and sufficient conditions for determinacy of equilibrium paths converging to the steady state in terms of the feedback from inflation to the prevailing monetary policy instrument. In what follows we will discuss these results in detail.

In a neighborhood of the steady state the equilibrium paths are approximated by the solutions to the linearized equilibrium conditions. The linearized versions of $(3)$ and the linearized aggregate production, $y-\bar{y}=l-\bar{l}$, are combined with (4) and the market clearing condition $y=c$, to the following linear approximations to the private sector equilibrium conditions

$$
\begin{aligned}
\dot{c} & =\left(\bar{c} / \sigma_{c}\right) \cdot(R-\bar{R})-\left(\bar{c} / \sigma_{c}\right) \cdot(\pi-\bar{\pi}), \\
\dot{\pi} & =-(\chi / \bar{c}) \cdot(c-\bar{c})+\theta \cdot(\pi-\bar{\pi}), \\
m-\bar{m} & =\sigma_{c}(\bar{m} / \bar{c}) \cdot(c-\bar{c})-(\bar{m} / \bar{R}) \cdot(R-\bar{R}),
\end{aligned}
$$

where $\chi=\delta(\delta+\theta) \frac{\varepsilon}{\varepsilon-1}\left(\sigma_{c}+\sigma_{l}\right)>0$. A perfect foresight equilibrium then consists of a set of paths for consumption, inflation, the nominal interest rate, and real balances that converge to the steady state and satisfy the linearized private sector equilibrium conditions and the linearized policy rules.

Consider an $I R$ or a $M G$ policy. When fiscal policy is characterized by $\kappa>0$, the transversality condition, which is given by $\lim _{t \rightarrow \infty} a(t) \exp \left\{-\int_{0}^{t}[R(v)-\pi(v)] d v\right\}=0$, is always satisfied for any set of equilibrium paths $\{c, \pi, R, m\}$, and the paths for real wealth and taxes are irrelevant. When the primary surplus is exogenous, $\kappa=0$, the transversality 
condition is not satisfied for any set of paths $\{c, \pi, R, m\}$ satisfying (15)-(17). The equilibrium paths $\{c, \pi, R, m\}$ are therefore not independent of $\{a, \tau=0\}$. Thus, an equilibrium is then defined in terms of paths $\{c, \pi, R, m, a\}$, and the set of equilibrium conditions includes the transversality condition and the linearized version of (11) for $s=a, R m=c^{\sigma_{c}}$, and $\kappa=0$ :

$$
\dot{a}=\theta(a-\bar{a})+\bar{a}(R-\bar{R})-\bar{a}(\pi-\bar{\pi})+\sigma^{c}(\bar{c})^{-\sigma_{c}-1}(c-\bar{c})
$$

where $\bar{a}=\bar{c}^{-\sigma_{c}} / \theta$, for a given initial value $a_{0}=A_{0} / P_{0}>0$. It should further be noted that under a $M G$ policy there exists an additional initial condition $m_{0}=M_{0} / P_{0}>0$, where $M_{0}$ is given by monetary policy. The following equilibrium definition therefore distinguishes between the two cases, $\kappa>0$ and $\kappa=0$, for an $I R$ policy and the two cases for a $M G$ policy. The last part describes the equilibrium under a $B M$ policy for $\kappa \geq 0$.

Definition 1 A perfect foresight equilibrium

1. under an IR policy and a primary surplus that rises with debt, $\kappa>0$, is a set of paths $\{c, \pi, R, m\}$ that converge to the steady state and satisfy (15)-(17) and $R-\bar{R}=\rho_{\pi}(\pi-\bar{\pi})$.

2. under an IR policy and an exogenous primary surplus, $\kappa=0$, is a set of paths $\{c, \pi, R, m, a\}$ that converge to the steady state and satisfy (15)-(17), the transversality condition, $R-\bar{R}=\rho_{\pi}(\pi-\bar{\pi})$ and (18), given $a_{0}>0$.

3. under a $M G$ policy and a primary surplus that rises with debt, $\kappa>0$, is a set of paths $\{c, \pi, R, m\}$ that converge to the steady state and satisfy (15)-(17) and $\dot{m}=$ $\bar{m}\left(\bar{\mu}_{\pi}-1\right)(\pi-\bar{\pi})$ with $m_{0}>0$.

4. under a MR policy and an exogenous primary surplus, $\kappa=0$, is a set of paths $\{c, \pi, R, m, a\}$ that converge to the steady state and satisfy (15)-(17), the transversality condition, $\dot{m}=\bar{m}\left(\bar{\mu}_{\pi}-1\right)(\pi-\bar{\pi})$ with $m_{0}>0$, and (18), given $a_{0}>0$.

5. under a BM policy and a primary surplus characterized by $\kappa \geq 0$ is a set of paths $\{c, \pi, R, m, a\}$ that converge to the steady state and satisfy (15)-(17), $(1+\beta)(m-\bar{m})=$ $(a-\bar{a})-\bar{m} \beta_{\pi}(\pi-\bar{\pi})$, and

$$
\dot{a}=[(1-\kappa) \bar{R}-\bar{\pi}](a-\bar{a})+(1-\kappa) \bar{a}(R-\bar{R})-\bar{a}(\pi-\bar{\pi})+(1-\kappa) \sigma^{c}(\bar{c})^{-\sigma_{c}-1}(c-\bar{c}),
$$

where $\bar{a}=(1-\kappa) \bar{c}^{-\sigma_{c}}[(1-\kappa) \bar{R}-\bar{\pi}]^{-1}$, given $a_{0}>0$.

Under an $I R$ or a $M G$ policy and an exogenous primary surplus, $\kappa=0$, government solvency is not ensured off equilibrium. Thus, the transversality condition imposes a binding restriction on the remaining variables, which demands real wealth to grow with a rate that is strictly smaller than the real interest rate. This requirement is responsible for the equilibrium values for consumption, inflation, the interest rate and real money to depend on current real wealth. Prices cannot jump due to the nominal rigidity and real wealth evolves, by (11) given $a_{0}>0$, in a history dependent way. Thus, real wealth serves as a relevant predetermined state variable. Existence of an equilibrium (that converges to the steady state) under an exogenous 
primary surplus therefore requires the real wealth path to be stationary. Hence, for $\kappa=0$, the linear approximation of (11) at the steady state enters the set of relevant equilibrium conditions (see 18). In contrast, the particular value of real wealth is irrelevant for the determination of the remaining variables if $\kappa>0$, and the existence of equilibrium paths $\{c, \pi, R, m\}$ that converge to the steady state does not rely on a bounded path for real wealth.

The equilibrium under a $B M$ policy differs with regard to two properties. Firstly, the equilibrium allocation is - even for a primary surplus that rises with debt $(\kappa>0)$ - in general not independent of real wealth. Secondly, government solvency is - even for a exogenous primary surplus $(\kappa=0)$ - guaranteed regardless of the private sector behavior. As a consequence, the linearized condition on the evolution of real wealth (19) becomes a relevant equilibrium condition for both types of fiscal policy regimes, while the transversality condition is irrelevant.

\subsubsection{Interest rate policy}

At first we reconsider, for convenience, the case where the central bank sets the nominal interest rate according to (6). The local dynamic properties for this case have already been examined by Leeper (1991) and Benhabib et al. (2001) in similar models. ${ }^{20}$ To assess local equilibrium determinacy, the interest rate is eliminated by the linearized policy rule $R-\bar{R}=\rho_{\pi}(\pi-\bar{\pi})$ in (15). For $\kappa>0$, local determinacy of the consumption and inflation paths requires both eigenvalues of the forward-looking differential equations (15) and (16) to be unstable, which calls for an active interest rate policy, $\bar{\rho}_{\pi}>1$ (see Benhabib et al., 2001). ${ }^{21}$ Real balances are then determined by (17). For $\kappa=0$, the existence of an equilibrium requires a stationary real wealth path. Interest rate policy then has to be passive, $\bar{\rho}_{\pi}<1$, to lead to one stable and two unstable eigenvalues for (15), (16) and (18). The stable eigenvalue is then assigned to the predetermined variable $(a)$.

Proposition 1 Suppose that the central bank sets the interest rate according to (6). Then,

1. there exists a unique perfect foresight equilibrium that converges to the steady state if and only if $\bar{\rho}_{\pi}>1$ for $\kappa>0$, or $\bar{\rho}_{\pi}<1$ for $\kappa=0$.

2. there exists a continuum of perfect foresight equilibria that converge to the steady state if and only if $\bar{\rho}_{\pi}<1$ and $\kappa>0$.

3. there exists no perfect foresight equilibrium that converges to the steady state if $\bar{\rho}_{\pi}>1$ and for $\kappa=0$.

\footnotetext{
${ }^{20}$ Benhabib et al. (2001) abstract from an endogenous labor supply decision, and Leeper (1991) applies a model with perfectly flexible prices.

${ }^{21}$ To be more precise, the product of the eigenvalues, $X_{1}$ and $X_{2}$, of (15) and (16) is given by $X_{1} X_{2}=$ $\left(\overline{\rho_{\pi}}-1\right) \chi / \sigma_{c}$ and their sum by $X_{1}+X_{2}=\theta>0$. Thus, both eigenvalues are unstable if and only if $\bar{\rho}_{\pi}>1$.
} 
When the primary surplus rises with debt $\kappa>0$, fiscal policy is neutral and the "Taylorprinciple" holds (see part 1 of proposition 1): The equilibrium is uniquely determined if and only if interest rate policy is active $\left(\bar{\rho}_{\pi}>1\right) .{ }^{22}$ The unique equilibrium solutions for consumption and inflation are constant and equal to their steady state values. When the primary surplus is exogenous, $\kappa=0$, these solutions would lead with (18) and $a_{0}>0$ to a real wealth path that violates the transversality condition. Hence, interest rate policy then has to be passive, which allows for multiple consumption and inflation paths that converge to the steady state. The transversality condition then imposes an additional restriction on the paths $\{c, \pi, a\}$. Thus, for $\kappa=0$ equilibrium determinacy requires interest rate policy to be accommodating, $\bar{\rho}_{\pi}<1$ (see part 2). Otherwise, $\kappa=0$ and $\bar{\rho}_{\pi}>1$, there exists no equilibrium that converges to the steady state (see part 3 ).

\subsubsection{Money growth policy}

Now consider the case where the central bank sets the money growth rate according to (7). Though equilibrium determinacy for $M G$ policy has already been analyzed in various studies (see Black, 1974, Matsuyama, 1990, Woodford, 1994, Matheny, 1998, or Carlstrom and Fuerst, 2003), the implications for local equilibrium determinacy for contingent money supply rules under sticky prices have (until now) not been examined. Eliminating the interest rate with (17) in (15), the set of equilibrium conditions is reduced to (16)

$$
\begin{aligned}
\dot{c} & =\bar{R} \cdot(c-\bar{c})-\frac{\bar{c}}{\sigma_{c}} \cdot(\pi-\bar{\pi})-\frac{\bar{c}}{\sigma_{c}} \frac{\bar{R}}{\bar{m}} \cdot(m-\bar{m}), \\
\dot{m} & =\bar{m}\left(\bar{\mu}_{\pi}-1\right) \cdot(\pi-\bar{\pi}),
\end{aligned}
$$

and (18) with the transversality condition if $\kappa=0$. Corresponding to the $I R$ policy case, real wealth does not affect the equilibrium paths for inflation, consumption, and real balances when fiscal policy satisfies $\kappa>0$. Since real balances evolve by (21) with $m_{0}>0$ in a history dependent way, $m$ is a predetermined state variable. Thus, local equilibrium determinacy requires (16), (20), and (21) to exhibit one stable and two unstable eigenvalues. An exogenous primary surplus, $\kappa=0$, introduces - like in the $I R$ case - an additional relevant predetermined variable, $a$, with an unstable eigenvalue, $\theta$ (see 18). As a consequence, local equilibrium determinacy then requires (16), (20), and (21) to exhibit one unstable and two stable eigenvalues. Then, (16), (20), and (21) exhibit multiple solutions for $\{c, \pi, m\}$, and (18) selects together with transversality condition one solution associated with a stationary real wealth path.

\footnotetext{
${ }^{22}$ When inflation is high and interest rate policy is passive, $\bar{\rho}_{\pi}<1$, the real interest rate declines, causing households to save less and to raise consumption (see 15). Higher aggregate demand then raises production costs and leads firms to raise their prices, by (16), such that inflation expectations can be self-fulfilling.
} 
Proposition 2 Suppose that the central bank supplies money according to (7) with $m_{0}>0$. Then,

1. there exists a unique perfect foresight equilibrium that converges to the steady state if and only if $\bar{\mu}_{\pi}<1$ for $\kappa>0$, or $\bar{\mu}_{\pi}>\max \{1, \widetilde{\mu}\}$ for $\kappa=0$.

2. there exists a continuum of perfect foresight equilibria that converge to the steady state if and only if $\bar{\mu}_{\pi}>\max \{1, \widetilde{\mu}\}$ and $\kappa>0$.

3. there exists no perfect foresight equilibrium that converges to the steady state if and only if $\bar{\mu}_{\pi} \in(1, \widetilde{\mu})$, or $\bar{\mu}_{\pi}<1$ and $\kappa=0$,

where $\widetilde{\mu}=\theta\left[\sigma_{c}(\bar{R}+\theta) \chi^{-1}-\bar{R}^{-1}\right]$.

Proof. See Appendix B.

Like for an $I R$ policy, local equilibrium determinacy depends on the central bank's response to changes in inflation $\bar{\mu}_{\pi}$ and on fiscal policy $\kappa$. When the primary surplus rises with debt, $\kappa>0$, the inflation response ought to be less than one $\bar{\mu}_{\pi}<1$ (see part 1 of proposition 2 ), such that higher inflation leads to decreasing real balances. For instance, a constant money growth rule $\left(\bar{\mu}_{\pi}=0\right)$ leads to local equilibrium determinacy. ${ }^{23}$ When the inflation response is larger than one $\bar{\mu}_{\pi}>1$, a rise in the inflation rate will be accompanied by an increase in the growth rate of real balances, leading to a stimulation of consumption and to a further increase in current inflation (see 16). In this case there exist either a continuum of equilibria or no equilibrium that converges to the steady state depending on whether $\bar{\mu}_{\pi}$ is smaller or larger than the threshold $\tilde{\mu}$. To be more precise, $\bar{\mu}_{\pi}>1$ leads to multiple solutions to (16), (20), and (21) when prices are sufficiently flexible, $\chi \geq R \theta \sigma_{c}$, such that $\widetilde{\mu} \leq 1$. If $\chi<R \theta \sigma_{c}$ and $\bar{\mu}_{\pi} \in(1, \widetilde{\mu})$, a rise in real balances in response to higher inflation will be accompanied by a strong stimulation of aggregate demand, such that there exists no equilibrium that converges back to the steady state.

On the contrary, an exogenous primary surplus, $\kappa=0$, requires money supply to be accommodating, $\bar{\mu}_{\pi}>1$, to ensure local equilibrium determinacy, whereas a non-accommodating money supply, $\bar{\mu}_{\pi}<1$, destabilizes the economy. If money supply satisfies $\bar{\mu}_{\pi}>\max \{1, \tilde{\mu}\}$, (16), (20), and (21) exhibit multiple solutions for the consumption, inflation, and real balances paths that converge to the steady state. From these multiple paths and the associated real wealth path, the transversality condition selects a unique set of paths $\{c, \pi, m, a\}$. Hence, in order to avoid unstable local dynamics, the central bank has to conduct monetary policy in a way that is inconsistent with a welfare enhancing stabilization of inflation; the latter evidently requires $\bar{\mu}_{\pi}<1$.

\footnotetext{
${ }^{23}$ Carlstrom and Fuerst (2003) show that a constant money growth policy also ensures equilibrium determinacy (for plausible money demand elasticities) in a flexible price cash-in-advance model.
} 
To summarize, an exogenous primary surplus $(\kappa=0)$ prevents an efficient conduct of monetary policy either under $I R$ or $M G$ policy, which would be characterized by a minimization of welfare losses due to the distortion stemming from imperfect price adjustments (see Woodford, 1996, 2003). Despite these similarities between both monetary policy regimes, the local dynamic analysis reveals that an $I R$ regime and a $M G$ regime, as specified in (6) and (7), cannot implement identical determinate equilibrium solutions. Evidently, a $M G$ regime always introduces an additional endogenous state variable $(m)$, leading to history dependent equilibrium paths (even when debt is neutral). ${ }^{24}$

\subsubsection{Controlling the bond-to-money ratio}

Finally, we consider the case where the central bank links the supply of money to the stock of outstanding government bonds according to (8). An adjustment in the ratio $\beta$ can be interpreted as an instantaneous change in the composition of liabilities via lump-sum transfers or open market operations. ${ }^{25}$ Suppose that the central bank raises the ratio $\beta(\pi)$ in response to higher inflation, $\beta_{\pi}>0$, such that money supply, $M=B / \beta(\pi)$, decreases for a given stock of government bonds. Households then tend to reduce consumption expenditures (see 17), which exerts a deflationary impact via the aggregate supply relation (21). ${ }^{26} \mathrm{~A}$ central bank that aims to stabilize inflation should therefore choose a positive inflation feedback $\beta_{\pi}>0$. As will be shown below, this recommendation relies on fiscal policy to choose a sufficiently large share of tax financing.

Eliminating the interest rate in (15) and real balances in (19) with (17) and $(1+\beta)(m-\bar{m})=$ $(a-\bar{a})-\bar{m} \beta_{\pi}(\pi-\bar{\pi})$, the set of equilibrium conditions can be reduced to (16),

$$
\begin{aligned}
& \dot{c}=\bar{R} \cdot(c-\bar{c})-\frac{1+\kappa \beta(\bar{\pi})-\theta \bar{\beta}_{\pi}}{1+\beta(\bar{\pi})} \frac{\bar{R} \bar{c}}{\theta \sigma_{c}} \cdot(\pi-\bar{\pi})-\frac{1}{1+\beta(\bar{\pi})} \frac{\bar{R} \bar{c}}{\bar{m} \sigma_{c}} \cdot(a-\bar{a}), \\
& \dot{a}=\beta(\bar{\pi})(1-\kappa) \frac{\bar{m} \bar{R}}{\bar{c}} \sigma_{c} \cdot(c-\bar{c})+\phi \cdot(\pi-\bar{\pi})-\beta(\bar{\pi}) \bar{R} \frac{1-\kappa}{1+\beta(\bar{\pi})} \cdot(a-\bar{a}),
\end{aligned}
$$

for $\kappa \in[0,1]$, where $\phi=\bar{m} \bar{R}\left\{(1-\kappa) \bar{\beta}_{\pi}-[1+\kappa \beta(\bar{\pi})] / \theta\right\}$. According to (22) real wealth affects consumption via changes in the nominal interest rate that are induced by shifts in the composition of public liabilities. Since real wealth evolves according to (23) in a history dependent way, it serves as a relevant predetermined state variable. Local equilibrium determinacy therefore requires the system (16), (22), and (23) to exhibit two unstable and one stable eigenvalue, regardless whether the primary surplus rises with debt $(\kappa>0)$ or is

\footnotetext{
${ }^{24} \mathrm{~A}$ comparison of fundamental equilibrium solutions under both regimes can be found in Schabert (2005).

${ }^{25}$ Our specification deviates from the one in Schreft and Smith $(1998,2000)$, where taxes are restricted to be equal to zero $(\kappa=0)$. Such a fiscal policy specification can be interpreted as money being supplied via open market operations (see Sargent and Smith, 1987, or Dupor, 2001b).

${ }^{26}$ Further details on the transmission of unanticipated changes in $\beta$ can be found in Heer and Schabert (2002) for a corresponding discrete time model.
} 
exogenous $(\kappa=0)$. For this, the central bank has to choose a sufficiently small value for the inflation feedback $\bar{\beta}_{\pi}$.

Proposition 3 Suppose that the central bank sets the bond-to-money ratio according to (8). Then, there exists a unique perfect foresight equilibrium that converges to the steady state if and only if

$$
(1-\kappa) \bar{\beta}_{\pi}<(1+\beta(\bar{\pi}) \kappa)^{2} / \theta
$$

Otherwise, $(1-\kappa) \bar{\beta}_{\pi}>(1+\beta(\bar{\pi}) \kappa)^{2} / \theta$, there exists no perfect foresight equilibrium that converges to the steady state.

\section{Proof. See Appendix C.}

According to proposition 3, monetary policy can ensure local equilibrium determinacy by choosing an inflation feedback $\bar{\beta}_{\pi}$ that satisfies (24). This constraint becomes more restrictive for smaller values for the debt feedback $\kappa$. Monetary policy is unconstrained for a balanced budget regime, $\kappa=1$, i.e., when interest rate obligations on outstanding debt are entirely tax financed. When the primary surplus is exogenous, $\kappa=0$, the upper bound in (24) takes the smallest value, and the condition on monetary policy reads, $\bar{\beta}_{\pi}<1 / \theta$. Given that $\theta$ equals the steady state real interest rate, even a moderate feedback satisfies the latter condition. The condition presented in proposition 3 thus implies that the central bank can always ensure the existence of a unique equilibrium that converges to the steady state by raising the bond-to-money ratio not too extremely in response to higher inflation. ${ }^{27}$

Corollary 1 Under a BM policy (8) there exists a unique perfect foresight equilibrium that converges to the steady state if $\bar{\beta}_{\pi}<1 / \theta$, or if the budget is permanently balanced $\kappa=1$.

The reason for a $B M$ policy satisfying $(24)$ or $\bar{\beta}_{\pi}<1 / \theta$ to exert a stabilizing impact on the economy can be rationalized as follows. Suppose that $\bar{\beta}_{\pi}>0$ and that inflation exceeds its steady state value. This tends to reduce the real value of total government liabilities. According to the monetary policy rule, real money also decreases by $1+\beta(\pi)$, such that the equilibrium interest rate rises (see 17) and households reduce consumption. Firms then lower their prices such that inflation returns to the steady state (see 16). At the same time, the increase in the interest rate raises debt payment obligations, such that nominal debt will rise if government expenditures are not completely tax financed (see 11). According to (23) for the case $\phi<0$, the real value of government liabilities will nevertheless decrease with inflation as long as the central bank's response to inflation is moderate $\bar{\beta}_{\pi}<1 / \theta$ or the share of tax financing $\kappa$ is large enough. ${ }^{28}$ In these cases, the central bank can stabilize inflation

\footnotetext{
${ }^{27}$ Evidently, pegging the ratio of bonds-to-money $\left(\bar{\beta}_{\pi}=0\right)$ is a safe strategy for a central bank to ensure local equilibrium determinacy. A constant bond-to-money ratio is also found to be favorable in the face of a perpetual decrease in the demand for cash (see Schreft and Smith, 2000).

${ }^{28}$ This effect can be read off the coefficient $\phi$ in $(23) \phi=\bar{m} \bar{R}\left\{(1-\kappa) \bar{\beta}_{\pi}-[1+\kappa \beta(\bar{\pi})] / \theta\right\}$, which is negative if $\bar{\beta}_{\pi}$ is sufficiently small. It should be noted that (24) does not ensure $\phi<0$.
} 
by a monetary tightening, i.e., by raising the bond-to-money ratio in response to an increase in inflation. In contrast to the cases of an accommodating $I R$ or $M G$ policy with $\kappa>0$, self-fulfilling inflation expectations cannot occur, since a rise in inflation alters the real value of debt in a way that tends to reduce aggregate demand and to bring down inflation.

Monetary policy can, however, be destabilizing when the central bank strongly raises the bond-to-money ratio in response to inflation under a fiscal policy regime where expenditures are not fully tax financed, such that $(1-\kappa) \bar{\beta}_{\pi}>(1+\beta(\bar{\pi}) \kappa)^{2} / \theta$. In this case, a rise in inflation leads to a strong increase in the ratio of government bonds to money. As a consequence, the equilibrium interest rate rises sharply, which causes the government to issue debt in a way that leads to a future rise in real wealth. This can be seen from (23) where the coefficient on inflation is now positive, $\phi>0$. Given that the bond-to-money ratio links money to real wealth, real balances will actually increase rather than decrease. This monetary expansion tends to raise inflation, and leads to a further rise in interest rates and real wealth. Thus, a very pronounced inflation feedback leads for $\kappa<1$ to a debt-interest spiral. ${ }^{29}$ Since debt feeds back to the equilibrium allocation, the economy will then not converge back to the steady state. Therefore, if (24) is violated, there exists no equilibrium that converges to the steady state.

Hence, a small share of tax financing can contribute to unstable debt dynamics, which render monetary stabilization policy impossible. This outcome is most likely when the primary surplus is exogenous $(\kappa=0)$. On this note, the latter fiscal policy regime is again most obstructive for the conduct of an inflation stabilizing monetary policy (like under an $I R$ or a $M G$ policy). If, however, interest payments on debt are fully tax financed $\kappa=1$, i.e., the budget is balanced, unstable debt dynamics cannot arise and local equilibrium determinacy is guaranteed. The conduct of monetary policy is then not constrained by fiscal policy, and the central bank can freely choose a high inflation feedback $\bar{\beta}_{\pi}$ in order to stabilize inflation. It should further be noted that a balanced budget policy is associated with a zero steady state inflation rate, $\bar{\pi}=0$, which minimizes the average distortion due to the nominal rigidity. Thus, under a bond-to-money regime fiscal policy can support a welfare maximizing monetary policy by keeping the budget balanced.

\section{Conclusion}

The literature on monetary policy and equilibrium determination has shown that the central banks' operating procedure should respect the particular fiscal policy stance in order to avoid equilibrium indeterminacy or instability. Whether a central bank that controls the nominal interest rate should react moderately rather than strongly to changes in inflation, depends on

\footnotetext{
${ }^{29} \mathrm{~A}$ similar result is found by Leith and Wren-Lewis (2000) in an overlapping generations model with sticky prices where public debt is also non-neutral with regard to private consumption.
} 
the response of the primary surplus to changes in public debt. If the primary surplus is raised with public debt, fiscal policy is neutral, and interest rate policy should aggressively respond to changes in inflation to stabilize inflation and, thereby, to avoid self-fulfilling expectations. If, however, the primary surplus is exogenous, such that fiscal policy does not ensure public sector solvency, interest rates should only moderately be adjusted in response to changes in inflation. Thus, the requirements for a stabilizing interest rate policy under both fiscal policy regimes are incompatible. This well-known principle is shown to apply in a corresponding way when the central bank sets the money growth rate (instead of the interest rate) contingent on changes in inflation. A successful stabilization of inflation by the central bank relies on an primary surplus that rises with debt. If, however, the primary surplus is exogenous, necessary devaluations of growing nominal debt requires the central bank to supply money in an accommodating way, such that nominal and real money balances grow in response to a rise in inflation.

While the determinacy implications of interest rate policy and money growth policy crucially depend on the particular fiscal policy, it is shown that the central bank can avoid being strongly constrained by fiscal policy under an alternative operating target. When the central bank links the supply of money to the outstanding stock of bonds (which both are typically traded in open market operations), the fiscal stance generally matters for the allocation and the price system. Put differently, by controlling the ratio of both types of government liabilities, monetary policy induces public debt to be non-neutral, which under the former monetary regimes has only been the case for an exogenous primary surplus. When the central bank controls the bond-to-money ratio, government solvency is further ensured for both types of fiscal policy. Moreover, the central bank is then hardly restricted by the requirements for local equilibrium determinacy, such that monetary policy can be conducted in an inflation stabilizing way. However, fiscal policy has an impact on long-run inflation and, therefore, on the average welfare costs of price rigidity. When taxes cover all interest payments on public debt, such that the budget is permanently balanced, long-run price stability as well as local equilibrium determinacy are ensured, regardless of how the central bank adjusts the bond-to-money ratio. 


\section{Appendix A: Derivation of the aggregate supply constraint}

The firm's problem is $\max _{Q_{t}} \int_{t}^{\infty} e^{-(\delta+\theta)(s-t)} \lambda_{s}\left[\left(Q_{t} e^{\bar{\pi}(s-t)} y_{i s}\left(Q_{t}\right)-P_{s} w_{s} n_{i s}\left(Q_{t}\right)\right) / P_{s}\right] d s$, subject to $y_{i} \leq\left(P_{i} / P\right)^{-\varepsilon} y, P^{1-\varepsilon}=\int_{0}^{1} P_{i}^{1-\varepsilon} d i$ and $y_{i}=l_{i}$. The first order condition is $\int_{t}^{\infty} e^{-(\delta+\theta)(s-t)} \frac{\lambda_{s}}{P_{s}}\left[(1-\varepsilon)\left(Q_{t} e^{\bar{\pi}(s-t)}\right)^{-\varepsilon} P_{s}^{\varepsilon} y_{s} e^{\bar{\pi}(s-t)}+\varepsilon\left(Q_{t} e^{\bar{\pi}(s-t)}\right)^{-\varepsilon-1} M C_{s} P_{s}^{\varepsilon} y_{s} e^{\bar{\pi}(s-t)}\right] d s=0$ where $M C$ denotes marginal costs, $M C_{s} y_{i s}=P_{s} w_{s} n_{i s}$. Simplifying and rearranging, this is equivalent to $\int_{t}^{\infty} e^{-(\delta+\theta)(s-t)} \lambda_{s}\left(P_{s}^{*}\right)^{\varepsilon-1} y_{s} Q_{t} d s=\frac{\varepsilon}{\varepsilon-1} \int_{t}^{\infty} e^{-(\delta+\theta)(s-t)} \lambda_{s}\left(P_{s}^{*}\right)^{\varepsilon-1} y_{s} M C_{s}^{*} d s$, where we define $X_{s}^{*} \equiv X_{s} / e^{\bar{\pi}(s-t)}$ for $X=P, M C$. Dividing both sides by $P_{t}$ and letting $q_{t} \equiv$ $Q_{t} / P_{t}$, we have $\int_{t}^{\infty} e^{-(\delta+\theta)(s-t)} \lambda_{s}\left(P_{s}^{*}\right)^{\varepsilon-1} y_{s} q_{t} d s=\frac{\varepsilon}{\varepsilon-1} \int_{t}^{\infty} e^{-(\delta+\theta)(s-t)} \lambda_{s}\left(P_{s}^{*}\right)^{\varepsilon-1} y_{s} M C_{s}^{*} \frac{1}{P_{t}} d s$. Linearizing this expression around the steady state, we obtain

$$
\begin{aligned}
& \int_{t}^{\infty} e^{-(\delta+\theta)(s-t)} \bar{\lambda}_{s}{\overline{P^{*}}}_{s}^{\varepsilon-1} \bar{y}_{s} \bar{q}_{t}\left[\frac{\lambda_{s}-\bar{\lambda}_{s}}{\bar{\lambda}_{s}}+(\varepsilon-1) \frac{P_{s}^{*}-\bar{P}_{s}^{*}}{\bar{P}_{s}}+\frac{y_{s}-\bar{y}_{s}}{\bar{y}_{s}}+\frac{q_{t}-\bar{q}_{t}}{\bar{q}_{t}}\right] d s \\
& =\frac{\varepsilon}{\varepsilon-1} \int_{t}^{\infty} e^{-(\delta+\theta)(s-t)} \bar{\lambda}_{s}{\overline{P^{*}}}_{s}^{\varepsilon-1} \bar{y}_{s} \overline{M C^{*}} s \frac{1}{\bar{P}_{t}}\left[\frac{\lambda_{s}-\bar{\lambda}_{s}}{\bar{\lambda}_{s}}+(\varepsilon-1) \frac{P_{s}^{*}-\bar{P}_{s}^{*}}{\bar{P}_{s}}+\right. \\
& \left.\frac{y_{s}-\bar{y}_{s}}{\bar{y}_{s}}+\frac{M C_{s}^{*}-\overline{M C}_{s}}{\overline{M C^{*}}{ }_{s}}-\frac{P_{t}-\bar{P}_{t}}{\bar{P}_{t}}\right] d s,
\end{aligned}
$$

where bars over variables denote the respective steady state values. Note that, in steady state, we have the following relations: $\bar{P}_{s}$ grows with the rate $\bar{\pi}$, whereas $\bar{P}^{*}$ is constant (as are $\overline{\lambda_{s}}$ and $\overline{y_{s}}$ ). Further, the price chosen by an adjusting firm must equal the aggregate price index, such that $\bar{q}_{t}=1$. The constant elasticity of the demand function implies that the steady state price level is a constant markup over nominal marginal costs, $\bar{P}_{s}=\varepsilon /(\varepsilon-1) \overline{M C}_{s}$. Therefore, as $\bar{P}_{s}=\bar{P}_{t} e^{\bar{\pi}(s-t)}$, we have that $\varepsilon /(\varepsilon-1) \overline{M C}^{*}{ }_{s} / \bar{P}_{t}=1$, and the coefficients on the left and right hand sides of (25) are the same. Hence, the equation simplifies to $\int_{t}^{\infty} e^{-(\delta+\theta)(s-t)} \frac{q_{t}-\bar{q}_{t}}{\bar{q}_{t}} d s=\int_{t}^{\infty} e^{-(\delta+\theta)(s-t)}\left[\frac{M C_{s}^{*}-\overline{M C^{*}} s}{\overline{M C^{*}} s_{s}}-\frac{P_{t}-\bar{P}_{t}}{\bar{P}_{t}}\right] d s$. Noting that $\left(M C_{s}^{*}-\overline{M C}^{*}\right) / \overline{M C^{*}}{ }_{s}=\left(M C_{s}-\overline{M C}_{s}\right) / \overline{M C}_{s}$ and defining real marginal costs as $m c_{s}=M C_{s} / P_{s}$, this can be written as

$$
\frac{q_{t}-\bar{q}_{t}}{\bar{q}_{t}}=(\delta+\theta) \int_{t}^{\infty} e^{-(\delta+\theta)(s-t)}\left[\frac{m c_{s}-\overline{m c}_{s}}{\overline{m c}_{s}}+\frac{P_{s} / P_{t}-\bar{P}_{s} / P_{t}}{\bar{P}_{s} / P_{t}}\right] d s .
$$

The last term in square brackets in the preceding expression is a function of the deviations of the inflation rates between $t$ and $s$ from steady state inflation, as from $P_{s} / P_{t}=\exp \left(\int_{t}^{s} \pi_{r} d r\right)$ it follows that $\left(P_{s} / P_{t}-\overline{P_{s} / P_{t}}\right) / \overline{P_{s} / P_{t}}=\int_{t}^{s}\left(\pi_{r}-\bar{\pi}\right) d r$. Using this and differentiating (26) with respect to $t$ we obtain by applying Leibniz' rule:

$$
\begin{aligned}
\frac{d}{d t} \frac{q_{t}-\bar{q}_{t}}{\bar{q}_{t}} & =-(\delta+\theta) \frac{m c_{s}-\overline{m c}_{s}}{\overline{m c}_{s}}+e^{-(\delta+\theta)(s-t)}\left[-\left(\pi_{t}-\overline{\pi_{t}}\right)\right] d s \\
& +(\delta+\theta) \int_{t}^{\infty}(\delta+\theta) e^{-(\delta+\theta)(s-t)}\left[\frac{m c_{s}-\overline{m c}_{s}}{\overline{m c}_{s}}+\int_{t}^{s}\left(\pi_{r}-\overline{\pi_{r}}\right) d r\right] \\
& =(\delta+\theta)\left[\frac{q_{t}-\bar{q}_{t}}{\bar{q}_{t}}-\frac{m c_{s}-\overline{m c}_{s}}{\overline{m c}_{s}}\right]-\left(\pi_{t}-\bar{\pi}_{t}\right) .
\end{aligned}
$$


This can be converted into a differential equation in $\pi$ by finding the relation between, respectively, the steady state deviations and the growth rates of inflation and the real reset price. First, the price index $P^{1-\varepsilon}=\left[\int_{0}^{1} P_{i}^{1-\varepsilon} \mathrm{d} i\right]$ can be expressed as a function of past reset prices, where each historical reset price has to be weighted by the probability that a price set at time $s$ is not adjusted in time $t$, which is given by $\delta \exp \{-\delta(t-s)\}$ (see Calvo, 1983, Benhabib et al., 2001). Therefore, the price index can be written as $P_{t}^{1-\varepsilon}=$ $\int_{-\infty}^{t} \delta e^{-\delta(t-s)} Q_{s}^{1-\varepsilon} d s$. Differentiating with respect to $t$ and linearizing around the steady state implies $\pi_{t}-\overline{\pi_{t}}=\delta\left(q_{t}-\overline{q_{t}}\right)$. Using the latter in (27) and noting that $\bar{q}_{t}=1$ and $\overline{m c}_{t}=(\varepsilon-1) / \varepsilon$, this finally results in the linearized economy's aggregate supply constraint $\dot{\pi}=\theta\left(\pi_{t}-\overline{\pi_{t}}\right)-\frac{\varepsilon \delta(\delta+\theta)}{\varepsilon-1}\left(m c_{t}-\overline{m c}_{t}\right)$.

\section{Appendix B: Local equilibrium determinacy for flexible prices}

We restrict our attention to equilibrium paths that converge to the steady state. A perfect foresight equilibrium under flexible prices $(\delta \rightarrow 0)$ consists of an initial price level $P_{0}>0$ and a set of paths $\{c, m, R, \pi, a, \tau\}$ that converge to the steady state and satisfy

$$
\begin{aligned}
c & =[(\varepsilon-1) / \varepsilon]^{1 /\left(\sigma_{c}+\sigma_{l}\right)}, \\
R & =\pi+\theta, \\
m & =c^{\sigma_{c}} / R, \\
\dot{a} & =[(1-\kappa) R-\pi] a-(1-\kappa) R m, \\
A_{0} / P_{0} & =\int_{0}^{\infty} \exp \left(-\int_{0}^{t}[R(v)-\pi(v)] d v\right)[R m+\tau] d t, \\
a_{0} & =A_{0} / P_{0},
\end{aligned}
$$

a monetary policy (6), (7) with $M_{0}>0$, or (8), and a fiscal policy (9), given $A_{0}>0$.

Suppose that monetary policy is characterized by an $I R$ policy, $R=\rho(\pi)$. For $\kappa>0$, taxes are a function of real wealth, real balances, and interest rates, $\tau=\kappa R(a-m)$. Using the latter to eliminate taxes in (32), gives the price level $P_{0}$ as a function of the real wealth path $\{a\}$ for a given set of paths $\{m, R, \pi\}$ and $A_{0}>0$. Thus, for $\kappa>0$ and a set of bounded paths $\{m, R, \pi\}$, any initial price level $P_{0}$ together with an associated initial value for real wealth $a_{0}$ (see 33) and an associated real wealth path $\{a\}$ (see 31) satisfy (32). For $\kappa=0$, government solvency is not guaranteed, implying that (32) is not satisfied for any set of paths $\{c, m, R(\pi), \pi, a\}$ satisfying (28)-(31) and (33) for a given $A_{0}>0$. The initial price level $P_{0}$ then has to adjust to satisfy (32). Since $\kappa=0$ determines the tax path, $\tau=0$, there exists exactly one initial price level $P_{0}$ that is consistent with a particular set of bounded paths $\{c, m, R, \pi\}$ and an initial value $A_{0}>0$.

To assess local determinacy of the set of equilibrium paths $\{c, m, R, \pi, a, \tau\}$, we use that $c$ equals its steady state value (see 28 ) and that $m$ is determined for a path $\{R\}$ (see 30). 
To identify the conditions for the local determination of the equilibrium paths for $\pi$ and $R$ we linearize $(29)$ and $R=\rho(\pi)$ at the steady state, which can be reduced to $\left(\rho_{\pi}-1\right)(\pi-$ $\bar{\pi})=0$. Inflation, and, therefore, the nominal interest rate and real balances, are locally determined if and only if $\rho(\bar{\pi}) \neq 1 \Rightarrow \pi=\bar{\pi}$. Real wealth can separately be determined by $\dot{a}=[(1-\kappa) R-\pi] a-(1-\kappa) R m$ for some initial value $a_{0}=A_{0} / P_{0}$. For $\kappa>0$, there exist infinitely many real wealth paths indexed with different initial price levels and initial values $A_{0} / P_{0}$, which are all consistent with the uniquely determined set of equilibrium paths $\{c, m, R, \pi\}$ and a particular initial value $A_{0}>0$. For $\kappa=0 \Rightarrow \tau=0$, there exist exactly one value for $P_{0}$ and one for $a_{0}$ that are consistent with the uniquely determined set of equilibrium paths $\{c, m, R, \pi\}$ and a given $A_{0}>0$. Hence, the local determination of an equilibrium that consists of $P_{0}$ and $\{c, m, R, \pi, a, \tau\}$ requires $\rho(\bar{\pi}) \neq 1$ and $\kappa=0$, whereas the equilibrium is indetermined for $\kappa>0$, since $P_{0}$ and $\{a, \tau\}$ cannot be determined. Nevertheless, the set of equilibrium paths $\{c, m, R, \pi\}$ is locally determined for $\kappa>0$ if $\rho(\bar{\pi}) \neq 1$.

Under $M G$ policy, the central bank supplies nominal money according to a money growth rate rule with an initial value $M_{0}>0$. Thus, there exists a unique price level path (including $\left.P_{0}\right)$ that is consistent with a particular set of paths $\{m, \pi\}$, since the nominal money $M$ is predetermined by monetary policy. To assess local determinacy of the set of equilibrium paths $\{c, m, R, \pi, a, \tau\}$, we again use that $c$ equals its steady state value (see 28 ). To identify the conditions for local determinacy of the equilibrium paths for $\pi, m$, and $R$ we eliminate $R$ in (29) with (30), and linearize the remaining condition and the policy rule, $\dot{m}=(\mu(\pi)-\pi) m$, at the steady state. Thus, real balances and inflation have to satisfy $-(\bar{\pi}+\theta)(m-\bar{m})=$ $\bar{m}(\pi-\bar{\pi})$ and $\dot{m}=\left(\bar{\mu}_{\pi}-1\right) \bar{m}(\pi-\bar{\pi})$, which can further be combined to $\dot{m}=\left(1-\bar{\mu}_{\pi}\right)(\bar{\pi}+$ $\theta)(m-\bar{m})$. For $\kappa>0$, a unique solution for $\{m\}$ requires the eigenvalue to be unstable, which is the case if and only if $\bar{\mu}_{\pi}<1$. The paths $\{c, R, \pi\}$ are then also locally determined as well as the price level path satisfying $P=M / m$. Finally, the path $\{a\}$ is determined by (31) and (33), and $\{\tau\}$ by (9). For an exogenous primary surplus $\kappa=0$, there exists - like under $I R$ policy - a unique pair $P_{0}$ and $a_{0}$ satisfying (32) and (33) that is consistent with a particular set of bounded paths $\{c, m, R, \pi\}$ and a given $A_{0}>0$. Thus, local equilibrium determinacy then requires money growth to satisfy $\bar{\mu}_{\pi}>1$, such that $\dot{m}=\left(1-\bar{\mu}_{\pi}\right)(\bar{\pi}+\theta)(m-\bar{m})$ exhibits multiple solutions for $m$. Condition (32) then imposes an additional restriction on the pair $P_{0}$ and $\{m\}$ that is consistent with money supply, and selects a unique set of equilibrium paths for real balances and thus for inflation, and consequently for the interest rate and for real wealth.

When the central bank sets the $B M$ ratio, i.e., $a=(1+\beta(\pi)) m$, there exists a unique real wealth path $\{a\}$ for a particular set of paths $\{m, \pi\}$. Thus, for any fiscal policy satisfying (9) with $\kappa \geq 0$, the RHS of (32) and therefore $P_{0}$ are uniquely determined for a bounded set of paths $\{c, m, R, \pi\}$ given $A_{0}>0$. At the same time, government solvency 
is already satisfied off equilibrium (see 14), such that the transversality condition never imposes an additional restriction on the price level. To assess local equilibrium determinacy, we again use that $c$ equals its steady state value (see 28). To identify the conditions for local determinacy of the equilibrium paths $\{m, R, \pi, a, \tau\}$, we log-linearize (29)-(31) and $a=(1+\beta(\pi)) m$, and eliminate $R, m$, and $\tau$. The remaining paths $\{\pi, a\}$ then have to satisfy $\dot{a}=\left((1-\kappa) \frac{(1+\beta(\bar{\pi})) \beta(\bar{\pi})+(\bar{\pi}+\theta) \bar{\beta}_{\pi}}{(1+\beta(\bar{\pi}))^{2}}-1\right)(\pi-\bar{\pi})$ and $(\pi-\bar{\pi})=\frac{(1+\beta(\bar{\pi}))(\bar{\pi}+\theta)}{\bar{a}(\bar{\pi}+\theta) \bar{\beta}_{\pi}-\bar{a}(1+\beta(\bar{\pi}))}(a-\bar{a})$. Using the steady state condition $\bar{\pi}=\theta(1-\kappa) \frac{\beta(\bar{\pi})}{1+\kappa \beta(\bar{\pi})}$, then gives

$$
\dot{a}=\left[(1-\kappa) \theta \bar{\beta}_{\pi}-(1+\kappa \beta(\bar{\pi}))^{2}\right]\left(\theta \bar{\beta}_{\pi}-(1+\kappa \beta(\bar{\pi}))\right)^{-1}\{\theta /(\bar{a}[1+\kappa \beta(\bar{\pi})])\} \cdot(a-\bar{a}) .
$$

If $\bar{\beta}_{\pi}<(1+\kappa \beta(\bar{\pi})) / \theta$, the eigenvalue is positive since $(1+\kappa \beta(\bar{\pi}))(1-\kappa)<(1+\kappa \beta(\bar{\pi}))^{2}$ and $\bar{a}>0$, given that $\beta<-1$. Then, there exists a unique solution for $\{a\}$ and therefore for the remaining paths $\{c, m, R, \pi, \tau\}$ and for $P_{0}$, indicating local equilibrium determinacy. A sufficient condition for local equilibrium determinacy is $\beta_{\pi}<1 / \theta$. The equilibrium is also locally determined if $\bar{\beta}_{\pi}(1-\kappa)>(1+\kappa \beta(\bar{\pi}))^{2} / \theta$.

\section{Appendix C: Proof of proposition 2}

In order to derive the conditions for local equilibrium determinacy, the system (16), (20), and (21) is rewritten as

$$
\left(\begin{array}{l}
\dot{c} \\
\dot{\pi} \\
\dot{m}
\end{array}\right)=\left(\begin{array}{ccc}
\bar{R} & -\frac{\bar{c}}{\sigma_{c}} & -\frac{\bar{c}}{\sigma_{c}} \frac{\bar{R}}{\bar{m}} \\
-\frac{\chi}{\bar{c}} & \theta & 0 \\
0 & \bar{m}\left(\bar{\mu}_{\pi}-1\right) & 0
\end{array}\right)\left(\begin{array}{l}
c-\bar{c} \\
\pi-\bar{\pi} \\
m-\bar{m}
\end{array}\right)=A^{\mu}\left(\begin{array}{l}
c-\bar{c} \\
\pi-\bar{\pi} \\
m-\bar{m}
\end{array}\right) .
$$

The trace of $A^{\mu}$ is positive, $\operatorname{tr}\left(A^{\mu}\right)=\bar{R}+\theta>0$, and the determinant is given by $\operatorname{det}\left(A^{\mu}\right)=$ $\frac{\bar{R} \chi}{\sigma_{c}}\left(\bar{\mu}_{\pi}-1\right)$. If $\bar{\mu}_{\pi}<1$, there are one stable and two unstable eigenvalues, indicating local equilibrium determinacy under endogenous taxes, $\kappa>0$. Under exogenous taxes, $\kappa=0$, stability and uniqueness require two stable eigenvalues and thus $\bar{\mu}_{\pi}>1$. For $\bar{\mu}_{\pi}>1, A^{\mu}$ can either have one or three unstable eigenvalues. To identify these cases, we use that $A^{\mu}$ exhibits three positive (unstable) roots when $-A^{\mu}$ has three negative (stable) roots, and the modified Routh-Hurwitz criterion (see, e.g., Braun, 1993). It says that a $3 \times 3$ matrix $X$ exhibits three stable eigenvalues if and only if $\operatorname{tr}(X)<0, \operatorname{det}(X)<0$, and the determinant of the matrix $\widetilde{X}$ is negative, where $\widetilde{X}$ (and for our case $-\widetilde{A}^{\mu}$ ) is defined by

$$
\widetilde{X}=\left(\begin{array}{ccc}
a_{11}^{\mu}+a_{22}^{\mu} & a_{23}^{\mu} & -a_{13}^{\mu} \\
a_{32}^{\mu} & a_{11}^{\mu}+a_{33}^{\mu} & a_{12}^{\mu} \\
-a_{31}^{\mu} & a_{21}^{\mu} & a_{22}^{\mu}+a_{33}^{\mu}
\end{array}\right) \Rightarrow-\widetilde{A}^{\mu}=\left(\begin{array}{ccc}
-(\bar{R}+\theta) & 0 & -\frac{\bar{c}}{\sigma_{c}} \frac{\bar{R}}{\bar{m}} \\
-\bar{m}\left(\bar{\mu}_{\pi}-1\right) & -\bar{R} & \frac{\bar{c}}{\sigma_{c}} \\
0 & \bar{\chi} & -\theta
\end{array}\right) .
$$

Given that $\operatorname{tr}\left(-A^{\mu}\right)=-(\bar{R}+\theta)<0$ and $\operatorname{det}\left(-A^{\mu}\right)<0$ for $\bar{\mu}_{\pi}>1$, all eigenvalues of $-A^{\mu}$ $\left(A^{\mu}\right)$ are stable (unstable) if and only if $\operatorname{det}\left(-\widetilde{A}^{\mu}\right)=\sigma_{c}^{-1}\left[\bar{R} \bar{\mu}_{\pi} \chi-\bar{R} \theta \sigma_{c}(\bar{R}+\theta)+\theta \chi\right]<0$. If, 
however, $\operatorname{det}\left(-\widetilde{A}^{\mu}\right)>0,-A^{\mu}$ exhibits one stable eigenvalue for $\bar{\mu}_{\pi}>1$. Thus, $A^{\mu}$ exhibits two stable eigenvalues if and only if $\bar{\mu}_{\pi}>\max \{1, \widetilde{\mu}\}$, where $\widetilde{\mu}=(\theta / \bar{R} \chi)\left[\bar{R} \sigma_{c}(\bar{R}+\theta)-\chi\right]$. In this case, exogenous taxes $(\kappa=0)$ are associated with locally stable and unique equilibrium paths, while endogenous taxes $(\kappa>0)$ are associated with local equilibrium indeterminacy. If $\bar{\mu}_{\pi}<\widetilde{\mu} \Rightarrow \operatorname{det}\left(-\widetilde{A}^{\mu}\right)<0, A^{\mu}$ exhibits three unstable eigenvalues for $\bar{\mu}_{\pi}>1$. Thus, instability arises if and only if $\bar{\mu}_{\pi} \in(1, \widetilde{\mu})$ for $\kappa \geq 0$, or $\bar{\mu}_{\pi}<1$ for $\kappa=0$.

\section{Appendix D: Proof of proposition 3}

In order to derive the conditions for local equilibrium determinacy under a $B M$ regime, the system (16), (22), and (23) is rewritten as

$$
\left(\begin{array}{l}
\dot{c} \\
\dot{\pi} \\
\dot{a}
\end{array}\right)=\left(\begin{array}{ccc}
\bar{R} & -\frac{1+\kappa \beta(\bar{\pi})-\theta \overline{\beta_{\pi}}}{1+\beta(\bar{\pi})} \frac{\bar{R} \bar{c}}{\theta \sigma_{c}} & -\frac{1}{1+\beta(\bar{\pi})} \frac{\bar{R} \bar{c}}{\bar{m} \sigma_{c}} \\
-\frac{\chi}{\bar{c}} & \theta & 0 \\
\beta(\bar{\pi})(1-\kappa) \frac{\bar{m} \bar{R}}{\bar{c}} \sigma_{c} & \phi & -\beta(\bar{\pi}) \bar{R} \frac{1-\kappa}{1+\beta(\bar{\pi})}
\end{array}\right)\left(\begin{array}{l}
c-\bar{c} \\
\pi-\bar{\pi} \\
a-\bar{a}
\end{array}\right)=A^{\beta}\left(\begin{array}{l}
c-\bar{c} \\
\pi-\bar{\pi} \\
a-\bar{a}
\end{array}\right) .
$$

The trace of $A^{\beta}$ is given by $\operatorname{tr}\left(A^{\beta}\right)=2 \theta>0$, where we used the steady state condition $\bar{R}=\theta \frac{1+\beta(\bar{\pi})}{1+\kappa \beta(\bar{\pi})}$. The determinant of $A^{\beta}$ reads

$$
\operatorname{det}\left(A^{\beta}\right)=-\frac{\bar{R}^{2} \chi}{(1+\beta(\bar{\pi}))^{2} \theta \sigma_{c}}\left[(1+\beta(\bar{\pi}) \kappa)^{2}-\theta \beta_{\pi}(1-\kappa)\right] .
$$

For local equilibrium stability and uniqueness $A^{\beta}$ has to exhibit exactly one stable eigenvalue, which is the case if and only if $(1-\kappa) \bar{\beta}_{\pi}<\frac{(1+\beta(\bar{\pi}) \kappa)^{2}}{\theta} \Rightarrow \operatorname{det}\left(A^{\beta}\right)<0$. For $(1-\kappa) \bar{\beta}_{\pi}>$ $\frac{(1+\beta(\bar{\pi}) \kappa)^{2}}{\theta} \Rightarrow \operatorname{det}\left(A^{\beta}\right)>0, A^{\beta}$ can have one or three unstable eigenvalues. To examine this, we use that $-A^{\beta}$ exhibits three stable eigenvalues if and only if $\operatorname{tr}\left(-A^{\beta}\right)<0$, $\operatorname{det}\left(-A^{\beta}\right)<0$, and $\operatorname{det}\left(-\widetilde{A}^{\beta}\right)<0$, where $-\widetilde{A}^{\beta}$ is defined as (see proof of proposition 2)

$$
-\widetilde{A}^{\beta}=\left(\begin{array}{ccc}
-(\bar{R}+\theta) & 0 & -\frac{1}{1+\beta(\bar{\pi})} \frac{\bar{R} c}{\bar{m} \sigma} \\
-\phi & -\bar{R}+\beta(\bar{\pi}) \bar{R} \frac{1-\kappa}{1+\beta(\bar{\pi})} & \frac{1+\kappa \beta(\bar{\pi})-\theta \bar{\beta}}{\bar{R} \overline{\bar{R}}} \\
1+\beta(\bar{\pi}) & \frac{\chi}{\theta \sigma} \\
\beta(\bar{\pi})(1-\kappa) \frac{\bar{m} \bar{R}}{\bar{c}} \sigma & \frac{\chi}{\bar{c}} & -\theta+\beta \bar{R} \frac{1-\kappa}{1+\beta(\bar{\pi})}
\end{array}\right) .
$$

While $\operatorname{tr}\left(-A^{\beta}\right)=-2 \theta<0$ and $\operatorname{det}\left(-A^{\beta}\right)<0$ for $(1-\kappa) \bar{\beta}_{\pi}>\frac{(1+\beta(\bar{\pi}) \kappa)^{2}}{\theta}$, the determinant of $-\widetilde{A}^{\beta}$ is given by $\operatorname{det}\left(-\widetilde{A}^{\beta}\right)=\frac{\theta}{(\kappa \beta(\bar{\pi})+1)^{2} \sigma}\left[(\kappa \beta(\bar{\pi})+1)^{2}\left(\chi-2 \sigma \theta^{2}\right)-\bar{\beta}_{\pi} \theta \chi(1+\right.$ $\kappa(1+2 \beta(\bar{\pi})))]$. The term in the square brackets is strictly negative for $\bar{\beta}_{\pi}>\widetilde{\beta}_{\pi}$, where $\widetilde{\beta}_{\pi}=\frac{(\kappa \beta(\bar{\pi})+1)^{2}}{\theta} \frac{1-2 \sigma \theta^{2} / \chi}{1+\kappa(1+2 \beta(\bar{\pi}))}$, such that $\operatorname{det}\left(-\widetilde{A}^{\beta}\right)<0$ for $\bar{\beta}_{\pi}>\frac{(1+\beta(\bar{\pi}) \kappa)^{2}}{\theta} \frac{1}{1-\kappa}$, given that $\frac{(1+\beta(\bar{\pi}) \kappa)^{2}}{\theta} \frac{1}{1-\kappa}>\widetilde{\beta}_{\pi}$. Thus, $A^{\beta}$ exhibits three unstable eigenvalues (indicating instability) if $(1-\kappa) \bar{\beta}_{\pi}>\frac{(1+\beta(\bar{\pi}) \kappa)^{2}}{\theta}$. 


\section{References}

Bhattacharya, J., and N. Kudoh, 2002, Tight Money Policies and Inflation Revisited, Canadian Journal of Economics 35, 185-217.

Barro, R.J., 1974, Are Government Bonds Net Wealth?, Journal of Political Economy 82, 1095-1118.

Benhabib, J., Schmitt-Grohé, S., and M. Uribe, 2001, Monetary Policy and Multiple Equilibria, American Economic Review 91, 167-185.

Black, F., 1974, Uniqueness of the Price Level in Monetary Growth Models with Rational Expectations, Journal of Economic Theory 7, 53-65.

Braun, M., 1993, Differential Equations and their Applications, 4th ed., New York: Springer.

Brueckner, M., and A. Schabert, 2003, Supply Side Effects of Monetary Policy and Equilibrium Multiplicity, Economics Letters 79, 205-211.

Calvo, G., 1983, Staggered Prices in a Utility-Maximizing Framework, Journal of Monetary Economics 12, 383-398.

Canzoneri, M.B., R. Cumby, and B. Diba, 2001, Is the Price Level Determined by the Needs of Fiscal Solvency?, American Economic Review 91, 1221-1238.

Carlstrom, C.T., and T.S. Fuerst, 1995, Interest Rate Rules vs. Money Growth Rules: A Welfare Comparison in a Cash-in-Advance Economy, Journal of Monetary Economics $36,247-267$.

Carlstrom, C.T., and T.S. Fuerst, 2001, Timing and Real Indeterminacy in Monetary Models, Journal of Monetary Economics 47, 285-298.

Carlstrom, C.T., and T.S. Fuerst, 2003, Money Growth Rules and Price Level Determinacy, Review of Economic Dynamics 6, 263-275.

Carlstrom, C.T., and T.S. Fuerst, 2005, Investment and Interest Rate Policy: A Discrete Time Analysis, Journal of Economic Theory 123, 4-20 .

Christiano, L.J., and T.J. Fitzgerald, 2000, Understanding the Fiscal Theory of the Price Level, NBER Working Paper 7668.

Collard, F., and H. Dellas, 2005, Poole in the New Keynesian Model, European Economic Review 49, 887-907.

De Fiore, F., and Z. Liu, 2005, Does Trade Openness Matter for Aggregate Instability?, Journal of Economics Dynamics and Control 29, 1165-1192 . 
Dupor, B., 2001a, Investment and Interest Rate Policy, Journal of Economic Theory 98, 85-113.

Dupor, B., 2001b, Ruling Out Pareto Dominated Monetary Equilibria, Journal of Economic Dynamics and Control 25, 1899-1910.

Gavin, W.T., B.D. Keen, and M.R. Pakko, 2004, The Monetary Instrument Matters, Federal Reserve Bank of St. Louis, Working Paper 2004-026a.

Heer, B., and A. Schabert, 2002, Open Market Shocks in a Business Cycle Model with Financial Intermediation, in: Hairault, J.-O. and H. Kempf (eds.), Market Imperfections and Macroeconomic Dynamics, Kluwer Academic Publishers.

Kaas, L., and G. Weinrich, 2003, Money and Growth in a Production Economy with Multiple Assets, Macroeconomic Dynamics 7, 670-690.

Kocherlakota, N., and C. Phelan, 1999, Explaining the Fiscal Theory of the Price Level, Federal Reserve Bank of Minneapolis Quarterly Review 23, 14-23.

Leeper, E., 1991, Equilibria under 'Active' and 'Passive' Monetary and Fiscal Policies, Journal of Monetary Economics 27, 129-147.

Leith, C., and S. Wren-Lewis, 2000, Interactions between Monetary and Fiscal Policy Rules, Economic Journal 110, C93-C108.

Matheny, K., 1998, Non-Neutral Responses to Money Supply Shocks when Consumption and Leisure are Pareto Substitutes, Economic Theory 11, 379-402.

Matsuyama, K., 1990, Sunspot Equilibria (Rational Bubbles) in a Model of Money-in-theUtility-Function, Journal of Monetary Economics 25, 137-144.

Meng, Q., 2002, Monetary Policy and Multiple Equilibria in a Cash-in-Advance Economy, Economics Letters 74, 165-170.

Niepelt, D., 2004, The Fiscal Myth of the Price Level, Quarterly Journal of Economics 119, 277-299.

Sargent, T.J., and B.D. Smith, 1987, Irrelevance of Open Market Operations in Some Economies with Government Currency Being Dominated in Rate of Return, American Economic Review 77, 78-92.

Schabert, A., 2005, Money Supply and the Implementation of Interest Rate Targets, CEPR Discussion Paper DP5094. 
Schmitt-Grohe, S. and Uribe, M., 2000, Price Level Determinacy and Monetary Policy under a Balanced-Budget Requirement, Journal of Monetary Economics 45, 211-246.

Schreft, S.L., and B.D. Smith, 1998, The Effects of Open Market Operations in a Model of Intermediation and Growth, Review of Economic Studies 65, 519-550.

Schreft, S.L., and B.D. Smith, 2000, The Evolution of Cash Transactions: Some Implications for Monetary Policy, Journal of Monetary Economics 46, 97-120.

Sidrauski, M., 1967, Rational Choice and Patterns of Growth in a Monetary Policy, American Economic Review, 57, 534-544.

Sims, C., 1994, A Simple Model for the Study of the Determination of the Price Level and the Interaction of Monetary and Fiscal Policy, Economic Theory 4, 381-399.

Wallace, N., 1984, Some of the Choices for Monetary Policy, Federal Reserve Bank of Minneapolis Quarterly Review 8,1.

Woodford, M., 1994, Monetary Policy and Price Level Determinacy in a Cash-in-Advance Economy, Economic Theory 4, 345-380.

Woodford, M., 1995, Price-Level Determinacy without Control of a Monetary Aggregate, Carnegie-Rochester Conference Series on Public Policy 43, 1-46.

Woodford, M., 1996, Control of the Public Debt: A Requirement for Price Stability, NBER Working Paper 5684.

Woodford, M., 2001, Fiscal Requirements for Price Stability, Journal of Money, Credit, and Banking 233, 669-727.

Woodford, M., 2003, Interest and Prices: Foundations of a Theory of Monetary Policy, Princeton: Princeton University Press. 
Table 1 Conditions for local equilibrium determinacy under flexible prices

\begin{tabular}{|l|c|c|}
\hline \hline & Primary surplus rising with debt $\kappa>0$ & Exogenous primary surplus $\kappa=0$ \\
\hline$I R$ policy & Local equilibrium indeterminacy & $\bar{\rho}_{\pi} \neq 1$ \\
\hline$M G$ policy & $\bar{\mu}_{\pi}<1$ & $\bar{\mu}_{\pi}>1$ \\
\hline$B M$ policy & $\bar{\beta}_{\pi}<[1+\kappa \beta(\bar{\pi})] / \theta$ or $\quad(1-\kappa) \bar{\beta}_{\pi}>[1+\kappa \beta(\bar{\pi})]^{2} / \theta$ \\
\hline
\end{tabular}

Note: The derivation of the local equilibrium determinacy conditions are given in appendix B.

Table 2 Conditions for local equilibrium determinacy under sticky prices

\begin{tabular}{|l|c|c|}
\hline \hline & Primary surplus rising with debt $\kappa>0$ & Exogenous primary surplus $\kappa=0$ \\
\hline$I R$ policy & $\bar{\rho}_{\pi}>1$ & $\bar{\rho}_{\pi}<1$ \\
\hline$M G$ policy & $\bar{\mu}_{\pi}<1$ & $\bar{\mu}_{\pi}>\max \{1, \widetilde{\mu}\}$ \\
\hline$B M$ policy & \multicolumn{2}{|c|}{$(1-\kappa) \bar{\beta}_{\pi}<[1+\beta(\bar{\pi}) \kappa]^{2} / \theta$} \\
\hline \hline
\end{tabular}

Note: The definition of the composite parameter $\widetilde{\mu}$ is given in proposition 2 . 